\title{
Assessing the Frequency and Risk Factors Associated with Gastroesophageal Reflux Disease (GERD) in Southern Punjab, Pakistan
}

\author{
Muhammad Fawad Rasool (iD) \\ Rimsha Sarwar' \\ Muhammad Subhan Arshad (iD) ${ }^{1,2}$ \\ Imran Imran ${ }^{3}$ \\ Hamid Saeed (D) ${ }^{4}$ \\ Abdul Majeed (D) \\ Muqarrab Akbar $^{5}$ \\ Muhammad Omer Chaudhry ${ }^{6}$ \\ Anees ur Rehman (ID) \\ Waseem Ashraf ${ }^{3}$ \\ Tanveer Ahmad ${ }^{7}$ \\ Waleed Badoghaish ${ }^{8}$ \\ Faleh Alqahtani (iD ${ }^{9}$ \\ 'Department of Pharmacy Practice, Faculty \\ of Pharmacy, Bahauddin Zakariya \\ University, Multan, 60800, Pakistan; \\ ${ }^{2}$ Department of Pharmacy, Southern \\ Punjab Institute of Health Sciences, Multan, \\ 60000, Pakistan; ${ }^{3}$ Department of \\ Pharmacology, Faculty of Pharmacy, \\ Bahauddin Zakariya University, Multan, \\ 60800, Pakistan; ${ }^{4}$ University College of \\ Pharmacy, Allama lqbal Campus, University \\ of the Punjab, Lahore, 54000, Pakistan; \\ ${ }^{5}$ Department of Political Science, \\ Bahauddin Zakariya University, Multan, \\ 60800, Pakistan; ${ }^{6}$ School of Economics, \\ Bahauddin Zakariya University, Multan, \\ 60800, Pakistan; ${ }^{7}$ Institute for Advanced \\ Biosciences (lab), CNRS UMR5309, \\ INSERM UI209, Grenoble Alpes \\ University, La Tronche, 38700, France; \\ ${ }^{8}$ Department of Internal Medicine, College \\ of Medicine, University of Tabuk, Tabuk, \\ $7 / 411$, Saudi Arabia; ${ }^{9}$ Department of \\ Pharmacology and Toxicology, College of \\ Pharmacy, King Saud University, Riyadh, \\ I I45I, Saudi Arabia
}

Correspondence: Muhammad Fawad

Rasool; Faleh Alqahtani

Email fawadrasool@bzu.edu.pk;

afaleh@ksu.edu.sa
Purpose: Gastroesophageal reflux disease (GERD) is a highly prevalent gastrointestinal disorder with modifiable risk factors and it is associated with considerable health and economic burden. The current study was conducted to assess the frequency and risk factors related to GERD in the previously unstudied population of Southern Punjab, Pakistan.

Methods: A cross-sectional study was conducted for assessing the frequency and risk factors of GERD by using a self-administered questionnaire. The gastroesophageal reflux disease questionnaire (GerdQ) was utilized to detect the presence of the disease.

Results: The study included 308 participants; among them, $55.2 \%$ were female and $44.8 \%$ were male. The participants diagnosed with GERD (GerdQ score $\geq 8$ ) were $26.6 \%$. The various risk factors like higher BMI, past disease and smoking history, frequent use of NSAIDs, soft drinks, pickles, and spicy foods were significantly associated with GERD.

Conclusion: The present study showed that GERD is prevalent in Southern Punjab and is associated with various modifiable risk factors. The ascendance of GERD can be prevented by public health education and awareness campaigns.

Keywords: gastroesophageal reflux, GERD, risk factors, Southern Punjab

\section{Introduction}

Gastroesophageal reflux disease (GERD) is the most commonly reported disorder of the upper part of the gastrointestinal tract (GIT) and it is defined as a condition, which develops when the acid reflux from the stomach occurs into the esophagus and causes troublesome symptoms. ${ }^{1,2}$ Heartburn and regurgitation are the most common symptoms of GERD. ${ }^{3}$ These symptoms can potentially affect the quality of life of patients. ${ }^{4}$ If left untreated, GERD may cause serious complications, morbidities, and economic burdens that may further necessitate lifestyle modifications, long-term management regimens, and surgical interventions. ${ }^{5}$ Moreover, Barrett's esophagus, esophageal stricture, and esophageal adenocarcinoma are the serious complications associated with GERD. ${ }^{6}$

GERD has multifactorial pathophysiology that involves gastroesophageal junction. ${ }^{7}$ The clinical picture and pathology of GERD are mainly induced by the following factors that include increased pressure and compliance on the junction, leading to pathological regurgitation of stomach acidic content. ${ }^{8}$ In addition to that, various genetic and environmental risk factors are reported likely to be associated with the development of disease. The different lifestyle factors like consumption of soft drinks, coffee/tea, and alcohol, smoking, body mass index (BMI), usage of 
nonsteroidal anti-inflammatory drugs (NSAIDs), and sleeping position are also considered to be associated with GERD. ${ }^{9}$

GERD has an estimated high prevalence globally with a wide range of variability among different populations because of differences in the risk factors. The worldwide prevalence of GERD reported in the recently published metaanalysis that analyzed 96 studies from 37 countries around the globe was $13.98 \%$. ${ }^{9}$ The prevalence rate of GERD was high among the western world, ie, North America (19.55\%) and Europe (14.12\%) as compared to Asia (12.92\%), while in Asia prevalence rate also varied, as it was highest in Iran $(18.43 \%)$ and lowest in China $(4.16 \%){ }^{9}$

The prevalence of GERD was $22.2 \%$ to $24.0 \%$ as reported by a few hospital-based studies in Pakistan. ${ }^{10-12}$ Due to limited data availability, a recently published global review did not provide the prevalence of GERD in Pakistan. ${ }^{9}$ No reported data regarding the prevalence of GERD was available from Southern Punjab, which is $52 \%$ of the total area of province Punjab with 34.7 M population. ${ }^{13}$ Therefore, if a study is conducted in Pakistan that can assess the frequency and risk factors associated with GERD it would have many implications.

The present study was conducted to investigate the frequency of GERD and its associated risk factors in Southern Punjab, Pakistan.

\section{Materials and Methods Study Design and Population}

A cross-sectional study was conducted by using a selfadministered, structured questionnaire at the Tehsil Headquarter (THQ) Hospital, Kot Addu, Southern Punjab. All the patients visiting the outpatient department from November 2019 to May 2020 were recruited for the study. The patients having age $\geq 10$ years old with GIT symptoms, who were willing to participate, were included in the study. The individuals having any comorbidity, unable to understand the questionnaire, or who had not completed the questionnaire were excluded. A sample size of 280 participants was calculated by using Daniel's formula ${ }^{14}$ based on the previously reported prevalence of GERD in Pakistan ${ }^{10}$ with the precision of $\pm 5 \%$ and a confidence interval of $95 \%$.

\section{Data Collection and Questionnaire}

To achieve the required sample size, the simple convenient sampling technique was utilized to collect data from patients with GIT symptoms who agreed to participate.
The data was collected by using a self-administered questionnaire under the supervision of a trained data collectors' team. First, participants were provided with a brief introduction to the study and guidelines regarding filling out the questionnaire. Participants who felt difficulty in filling the questionnaire were assisted.

The questionnaire is comprised of three parts detailed in Supplementary Table S1. The first part consisted of questions about demographic data of patients, the second part was about the lifestyle and risk factors for the development of GERD and the third part was a diagnostic tool for GERD i.e., gastroesophageal reflux disease questionnaire (GerdQ). The GerdQ has $65 \%$ sensitivity and $71 \%$ specificity for the diagnosis of GERD. ${ }^{15}$ The participants having a GerdQ score of $\geq 8$ were considered to have the disease.

\section{Ethical Approval}

The written informed consent was received from each participant or from the parent or the legal guardian of the participant under the age of 18 years before the administration of the questionnaire. The study was conducted in accordance with the Declaration of Helsinki. The current study was approved by the ethics committee of the Department of Pharmacy Practice, Faculty of Pharmacy, Bahauddin Zakariya University Multan, Pakistan against reference number Acad/PRAC/18-20/06.

\section{Statistical Analysis}

The descriptive and inferential analysis was performed by utilizing a statistical package for the social sciences (SPSS) version 21.0 (IBM SPSS Statistics, New York, USA). The frequencies and percentages were used to present the categorical variables in descriptive analysis. While the association of lifestyle factors and risk factors with the presence or absence of GERD was analyzed by using the Chi-square $\left(\chi^{2}\right)$ test or Fisher's exact test as per need. To identify the possible predictors of GERD, univariate logistic regression analysis was performed. The odds ratios (ORs) with $95 \%$ confidence interval (CI) were used to express the results of the regression analysis. The significantly associated variables from the $\chi^{2}$ test were only included in the regression analysis. An alpha value of $<0.05$ was considered statistically significant.

\section{Results}

\section{Sociodemographic Characteristics}

A total of 489 questionnaires were distributed among the individuals who agreed to participate, out of which only 
315 questionnaires were collected back and lead to a response rate of $64.4 \%$. Seven questionnaires were excluded from the final analysis due to doubling in the GerdQ part of the questionnaire. Out of 308 participants, $170(55.2 \%)$ were female while among them $188(61.0 \%)$ had ages ranging from 30 to 39 years. More than half of the participants $(59.7 \%)$ were living in urban areas and the majority $(46.8 \%)$ had a university degree. The sociodemographic characteristics of the participants are presented in Table 1.

\section{Frequency of Gastroesophageal Reflux Disease}

The participants were diagnosed with GERD based on the GerdQ score of $\geq 8$. Among the 308 participants, 82 $(26.6 \%)$ were diagnosed with symptomatic GERD while $226(73.4 \%)$ had a GerdQ score of less than eight. The participants with GERD had statistically significant differences in sociodemographic characteristics (gender, living place, and social life) except age and education level as compared to those without GERD.

\section{Risk Factors and Lifestyle Characteristics Related to GERD}

The researcher team calculated the body mass index (BMI) of the participants that were categorized as normal weight
(18.5-24.9 kg/m²), overweight $\left(25-29.9 \mathrm{~kg} / \mathrm{m}^{2}\right)$, and obese $\left(\geq 30 \mathrm{~kg} / \mathrm{m}^{2}\right)$. Out of 308 participants, 77 (25.1\%) were normal weight, while $171(55.7 \%)$ and 59 (19.2\%) were overweight and obese, respectively. There was a significant difference $(p=0.008)$ between GERDdiagnosed individuals across BMI groups. The history of GIT disease was also significantly associated $(p<0.001)$ with the presence or absence of GERD. The details of the difference between GERD and No GERD patients across different risk factors and lifestyle characteristics are presented in Table 2.

There were significant differences in the majority of lifestyle factors (i.e., smoking history, chew pan masala, frequently use NSAIDs, frequently use soft drinks, frequently eat pickles, or frequently eat spicy meals) of GERD and no GERD participants. Among the GERD participants, the majority consume soft drinks $(61.0 \%)$ and ate spicy meals (59.8\%) frequently.

\section{The Predictors Associated with GERD}

The variables having a significant difference between the GERD and No GERD participants were selected for logistic regression analysis to assess the potential predictors. The selected variables were statistically significant predictors of GERD as shown in Table 3. The male participants were 1.73 times more prone to GERD as compared to

Table I Socio-Demographic Characteristics of the Study Participants

\begin{tabular}{|c|c|c|c|c|c|c|c|c|}
\hline \multicolumn{2}{|c|}{ Characteristics } & \multicolumn{2}{|c|}{ Total $(\mathbf{N}=308)$} & \multicolumn{2}{|c|}{ GERD ( $\mathbf{N}=82)$} & \multicolumn{2}{|c|}{ No GERD $(\mathrm{N}=226)$} & \multirow[t]{2}{*}{$P$-value } \\
\hline & & $\mathbf{N}$ & $\%$ & $\mathbf{N}$ & $\%$ & $\mathbf{N}$ & $\%$ & \\
\hline \multirow[t]{2}{*}{ Gender } & Male & 138 & 44.8 & 45 & 32.6 & 93 & 67.4 & 0.032 \\
\hline & Female & 170 & 55.2 & 37 & 21.8 & 133 & 78.2 & \\
\hline \multirow[t]{6}{*}{ Age (years) } & $10-19$ & 24 & 7.8 & 06 & 25.0 & 18 & 75.0 & 0.585 \\
\hline & $20-29$ & 22 & 7.1 & 06 & 27.3 & 16 & 72.7 & \\
\hline & $30-39$ & 188 & 61.0 & 49 & 26.1 & 139 & 73.9 & \\
\hline & $40-49$ & 35 & 11.4 & 08 & 22.9 & 27 & 77.1 & \\
\hline & $50-59$ & 35 & II.4 & 13 & 37.1 & 22 & 62.9 & \\
\hline & $\geq 60$ & 4 & 1.3 & 00 & 0.0 & 04 & 100.0 & \\
\hline \multirow{2}{*}{ Living place } & Urban & 184 & 59.7 & 62 & 33.7 & 122 & 66.3 & 0.001 \\
\hline & Rural & 124 & 40.3 & 20 & 16.1 & 104 & 83.9 & \\
\hline \multirow[t]{3}{*}{ Education level } & Primary/Middle & 40 & 13.0 & 09 & 22.5 & 31 & 77.5 & 0.227 \\
\hline & Secondary/Intermediate & 124 & 40.3 & 28 & 22.6 & 96 & 77.4 & \\
\hline & University degree & 144 & 46.8 & 45 & 31.3 & 99 & 68.8 & \\
\hline \multirow[t]{2}{*}{ Social life } & Living alone & 50 & 16.2 & 27 & 54.0 & 23 & 46.0 & $<0.001$ \\
\hline & With family & 258 & 83.8 & 55 & 21.3 & 203 & 78.7 & \\
\hline
\end{tabular}

Note: Bold fonts indicate the statistical significant $p$-value $(<0.05)$.

Abbreviation: GERD, gastroesophageal reflux disease. 
Table 2 Comparison of Risk Factors and Lifestyle Characteristics Among GERD and No GERD Participants

\begin{tabular}{|c|c|c|c|c|c|c|c|c|}
\hline & & \multicolumn{2}{|c|}{ Total $(\mathbf{N}=\mathbf{3 0 8})$} & \multicolumn{2}{|c|}{ GERD $(\mathbf{N}=82)$} & \multicolumn{2}{|c|}{ No GERD ( $N=226)$} & \multirow[t]{2}{*}{$P$-value } \\
\hline & & $\mathbf{N}$ & $\%$ & $\mathbf{N}$ & $\%$ & $\mathbf{N}$ & $\%$ & \\
\hline \multirow[t]{3}{*}{ BMI groups } & Normal weight & 77 & 25.1 & 13 & 16.9 & 64 & 83.1 & 0.008 \\
\hline & Overweight & $17 \mid$ & 55.7 & 45 & 26.3 & 126 & 73.7 & \\
\hline & Obese & 59 & 19.2 & 24 & 40.7 & 35 & 59.3 & \\
\hline \multirow[t]{2}{*}{ Past GIT disease history } & Yes & 42 & 13.6 & 38 & 90.5 & 4 & 9.5 & $<0.001$ \\
\hline & No & 266 & 86.4 & 44 & 16.5 & 222 & 83.5 & \\
\hline \multirow[t]{2}{*}{ Smoking history } & Yes & 32 & 10.4 & 26 & 81.3 & 6 & 18.8 & $<0.001$ \\
\hline & No & 276 & 89.6 & 56 & 20.3 & 220 & 79.7 & \\
\hline \multirow[t]{2}{*}{ Chew pan masala } & Yes & 10 & 3.2 & 8 & 80.0 & 2 & 20.0 & $<0.001$ \\
\hline & No & 298 & 96.8 & 74 & 24.8 & 224 & 75.2 & \\
\hline \multirow[t]{2}{*}{ Frequently use NSAIDs } & Yes & 20 & 6.5 & 12 & 60.0 & 8 & 40.0 & $<0.001$ \\
\hline & No & 288 & 93.5 & 70 & 24.3 & 218 & 75.7 & \\
\hline \multirow[t]{2}{*}{ Frequently use $\mathrm{CCB} /$ Nitrate } & Yes & 46 & 14.9 & 13 & 28.3 & 33 & 71.7 & 0.785 \\
\hline & No & 262 & 85.1 & 69 & 26.3 & 193 & 73.7 & \\
\hline \multirow[t]{2}{*}{ Frequently use soft drinks } & Yes & 148 & 48.1 & 50 & 33.8 & 98 & 66.2 & 0.006 \\
\hline & No & 160 & 51.9 & 32 & 20.0 & 128 & 80.0 & \\
\hline \multirow[t]{2}{*}{ Frequently consume tea } & Yes & 258 & 83.8 & 68 & 26.4 & 190 & 73.6 & 0.810 \\
\hline & No & 50 & 16.2 & 14 & 28.0 & 36 & 72.0 & \\
\hline \multirow[t]{2}{*}{ Frequently use of fried food } & Yes & 269 & 87.3 & 70 & 26.0 & 199 & 74.0 & 0.531 \\
\hline & No & 39 & 12.7 & 12 & 30.8 & 27 & 69.2 & \\
\hline \multirow[t]{2}{*}{ Frequently eat pickles } & Yes & 92 & 29.9 & 33 & 35.9 & 59 & 64.1 & 0.017 \\
\hline & No & 216 & 70.1 & 49 & 22.7 & 167 & 77.3 & \\
\hline \multirow[t]{2}{*}{ Frequently eat spicy meals } & Yes & 152 & 49.4 & 49 & 32.2 & 103 & 67.8 & 0.028 \\
\hline & No & 156 & 50.6 & 33 & 21.2 & 123 & 78.8 & \\
\hline
\end{tabular}

Note: Bold fonts indicate the statistical significant $p$-value $(<0.05)$.

Abbreviations: GERD, gastroesophageal reflux disease; BMI, body mass index; GIT, gastrointestinal tract; NSAIDs, non-steroidal anti-inflammatory drugs; CCB, calcium channel blocker.

females. The GERD was 4.33 times more common among the participants living alone as compared to those who were living with their families. The participants with past GIT disease and smoking history were 47.93 and 17.02 times more diagnosed with GERD as compared to other participants. The frequent use of NSAIDs and soft drinks predicted with GERD 4.67 and 2.04 times more than its non-users.

\section{Discussion}

To the best of our knowledge, the current study for the very first time determined the frequency of GERD in Southern Punjab, Pakistan, along with various factors associated with the development of disease. Based on the results of GerdQ, $26.6 \%$ of the participants were diagnosed with GERD. A similar rate of $24.0 \%$ was reported by a study from Pakistan published in $2005 .{ }^{12}$ A systematic review has reported the prevalence rates of 5.2-8.5\% and 6.3-18.3\% for GERD in Eastern Asia and Western and Southeast Asia. ${ }^{16}$ While a recent review based on 102-studies reported a global prevalence of GERD around 13.98\%, which ranges highest from Turkey $22.40 \%$ to the lowest in China $4.16 \%{ }^{9}$

The results of the current study indicated that GERD was more common among the male participants, which is consistent with previous studies from Pakistan. ${ }^{12,17,18}$ Similar results were also reported by the studies from other Asian countries. ${ }^{19-21}$ Our study also revealed the significant difference in the occurrence of GERD across the residential areas of the participants (Urban > Rural) which is consistent with a previous report from Pakistan. ${ }^{18}$ A review of different studies around the Globe also 
Table 3 The Logistic Regression Analysis to Assess Important Predictors of GERD

\begin{tabular}{|c|c|c|c|c|c|c|c|c|}
\hline \multicolumn{2}{|l|}{ Predictors } & \multirow{2}{*}{$\begin{array}{c}\text { B } \\
0.55\end{array}$} & \multirow{2}{*}{$\begin{array}{c}\text { SE } \\
0.26\end{array}$} & \multirow{2}{*}{$\frac{\text { Wald }}{4.53}$} & \multirow{2}{*}{$\frac{P \text {-value }}{0.033}$} & \multirow{2}{*}{$\frac{\text { OR }}{1.73}$} & \multirow{2}{*}{$\frac{\text { Lower }}{1.04}$} & \multirow{2}{*}{$\begin{array}{c}\text { Upper } \\
2.89\end{array}$} \\
\hline Gender & Male-Female & & & & & & & \\
\hline Living place & Urban-Rural & 0.97 & 0.29 & 11.25 & 0.001 & 2.64 & 1.49 & 4.66 \\
\hline Social life & Living alone-with family & 1.46 & 0.32 & 20.74 & $<0.001$ & 4.33 & 2.30 & 8.14 \\
\hline \multirow[t]{2}{*}{ BMI groups } & Overweight-Normal & 0.56 & 0.35 & 2.50 & 0.107 & 1.76 & 0.89 & 3.49 \\
\hline & Obese-Normal & 1.22 & 0.40 & 9.09 & 0.003 & 3.38 & 1.53 & 7.44 \\
\hline Past GIT disease history & Yes-No & 3.87 & 0.55 & 49.33 & $<0.001$ & 47.93 & 16.28 & 141.12 \\
\hline Smoking history & Yes-No & 2.83 & 0.47 & 35.31 & $<0.001$ & 17.02 & 6.68 & 43.35 \\
\hline Chew Pan masala & Yes-No & 2.49 & 0.80 & 9.67 & 0.002 & 12.10 & 2.51 & 58.29 \\
\hline Frequently use NSAIDs & Yes-No & 1.54 & 0.47 & 10.45 & 0.001 & 4.67 & 1.83 & 11.89 \\
\hline Frequently use soft drinks & Yes-No & 0.71 & 0.26 & 7.34 & 0.007 & 2.04 & 1.21 & 3.41 \\
\hline Frequently eat pickles & Yes-No & 0.64 & 0.27 & 5.65 & 0.017 & 1.90 & 1.12 & 3.24 \\
\hline Frequently eat spicy meals & Yes-No & 0.57 & 0.26 & 4.78 & 0.029 & 1.77 & 1.06 & 2.96 \\
\hline
\end{tabular}

Note: Bold fonts indicates the statistical significant $p$-value $(<0.05)$.

Abbreviations: GERD; Gastroesophageal Reflux Disease, BMI; Body Mass Index, GIT; Gastrointestinal Tract, NSAIDs; Non-Steroidal Anti-Inflammatory Drugs, SE; Standard Error, OR; Odds Ratio

revealed a higher prevalence of GERD among participants living in urban areas. ${ }^{9}$ The unhealthy dietary habits and physical inactivity among the urban population may be linked to the high prevalence of GERD in participants living in urban areas. ${ }^{22}$ The frequency of GERD among the overweight and obese study participants was high. Similar findings are reported by the different studies. ${ }^{9,20,23-25}$ Pathophysiological changes like lower esophageal sphincter abnormalities, esophageal motor disorders, and increased intragastric pressure due to obesity are the reasons for high prevalence among individuals with higher BMI ${ }^{26}$ The GERD symptoms were more prevalent in participants with a history of GIT disease. These results are consistent with a previously published report in which the majority of participants had a previous history of dyspepsia, GERD, and peptic ulcer disease. ${ }^{10}$

Lifestyle characteristics play an important role in the development of GERD. Different lifestyle factors like smoking history, chewing of pan masala, frequent use of NSAIDs, soft drinks, pickles, and spicy meals were significantly associated with the occurrence of GERD in the current study. The high prevalence of GERD in pan masala chewers has been reported previously in studies from South-East Asia. ${ }^{27,28}$ The pan masala is also a form of chewable tobacco that contains betel leaf, tobacco, lime, and sometimes Katha paste also. These ingredients may reduce the pressure of the lower esophageal sphincter during chewing, which could be the reason for the association of pan masala with the development of GERD. ${ }^{28}$ Previous studies from Pakistan also reported the frequent use of NSAIDs and spicy fried meals as significant factors related to the development of GERD. ${ }^{12,18}$ A recently published review also reported a high global prevalence rate of GERD in smokers and frequent users of NSAIDs and carbonated drinks. ${ }^{9}$ Smoking causes the reduction in lower esophageal sphincter pressure, ${ }^{29}$ while carbonated drinks increase the gastric acid volume, which causes acid reflux. ${ }^{30}$

The current study identified various modifiable risk factors of GERD, which may be the cause of the high frequency of GERD in the studied population. Pakistan is the ninth most obese nation in the world while these numbers are still growing. ${ }^{31}$ The prevalence of tobacco use is increasing day by day in the Pakistani population, which is also a major risk factor to the development of diseases including GERD. ${ }^{32}$ Keeping in view the increasing trend of risk factors associated with GERD in Pakistan, it is expected that its frequency will increase in coming years.

\section{Strength and Limitation}

The study utilized GerdQ for the diagnosis of GERD, which is a well-validated and reliable tool with reported 
high sensitivity and specificity, ${ }^{15}$ which can be accounted as its strength. The assessment of participants in the study was done on a symptoms-based approach and a relatively small sample size was used which may be a potential limitation of this study.

\section{Conclusion and Recommendations}

This study revealed that GERD is highly prevalent in Southern Punjab, Pakistan. The current study also identified many modifiable risk factors that can considerably affect the ascendance of the disease. The burden of disease can be reduced by managing these risk factors through public awareness and health education campaigns. In the future, detailed studies with a larger portion of the population are required for a more descriptive analysis of risk factors and prevalence of the disease.

\section{Abbreviations}

GERD, gastroesophageal reflux disease; BMI, body mass index; GIT, gastrointestinal tract; NSAIDs, non-steroidal anti-inflammatory drugs; CCB, calcium channel blocker; $\mathrm{OR}$, odds ratio; SE, standard error.

\section{Acknowledgment}

The authors extended their appreciation to the Distinguished Scientist Fellowship program at King Saud University, Riyadh, Saudi Arabia for funding this work through Research Supporting Project Number (RSP2021/131).

\section{Funding}

This work was funded by the Distinguished Scientist Fellowship program at King Saud University, Riyadh, Saudi Arabia, through research supporting project Number (RSP-2021/131).

\section{Disclosure}

The authors report no conflicts of interest in this work.

\section{References}

1. Hungin APS, Molloy-Bland M, Scarpignato C. Revisiting Montreal: new insights into symptoms and their causes, and implications for the future of GERD. Am J Gastroenterol. 2019;114(3):414. doi:10.1038/ s41395-018-0287-1

2. Vakil N, Van Zanten SV, Kahrilas P, Dent J, Jones R. The Montreal definition and classification of gastroesophageal reflux disease: a global evidence-based consensus. ACG. 2006;101(8):1900-1920.

3. Estores DS. Symptom predictability in gastroesophageal reflux disease and role of proton pump inhibitor test. Gastroenterol Clin. 2014;43 (1):27-38. doi:10.1016/j.gtc.2013.11.002
4. Isshi K, Furuhashi H, Koizumi A, Nakada K. Effects of coexisting upper gastrointestinal symptoms on daily life and quality of life in patients with gastroesophageal reflux disease symptoms. Esophagus. 2021;18(3):684-692. doi:10.1007/s10388-020-00801-1

5. Guan XL, Wang H. Quality of life scales for patients with gastroesophageal reflux disease: a literature review. Int J Nurs Sci. 2015;2 (1):110-114. doi:10.1016/j.ijnss.2015.02.003

6. Fontan FM, Carroll RS, Thompson D, Lehmann RK, Smith JK, Nau PN. Current management of gastroesophageal reflux disease in the obese population-a review of the literature. Mini Invasive Surg. 2020;4:29.

7. Menezes MA, Herbella FA. Pathophysiology of gastroesophageal reflux disease. World J Surg. 2017;41(7):1666-1671. doi:10.1007/ s00268-017-3952-4

8. Samo S, Qayed E. Esophagogastric junction outflow obstruction: where are we now in diagnosis and management? World J Gastroenterol. 2019;25(4):411. doi:10.3748/wjg.v25.i4.411

9. Nirwan JS, Hasan SS, Conway BR, Ghori MU. Global prevalence and risk factors of gastro-oesophageal reflux disease (GORD): systematic review with meta-analysis. Sci Rep. 2020;10(1):1-14. doi:10.1038/s41598-020-62795-1

10. Butt AK, Hashemy I. Risk factors and prescription patterns of gastroesophageal reflux disease: HEAL study in Pakistan. $J$ Pak Med Assoc. 2014;64(7):751-757.

11. Riaz H, Kamal SW, Aziz S. Students' Corner Gastroesophageal reflux disease (GERD) in students of a government medical college at Karachi. JPMA. 2010;60(2):147.

12. Jafri N, Jafri W, Yakoob J, et al. Perception of gastroesophageal reflux disease in urban population in Pakistan. JCPSP. 2005;15 (9):532-534.

13. PBS. Population Census. Available from: https://www.pbs.gov.pk/ content/final-results-census-2017. Accessed August 10, 2021.

14. Daniel WW, Cross CL. Biostatistics: A Foundation for Analysis in the Health Sciences. Wiley; 2018.

15. Jones R, Junghard O, Dent J, et al. Development of the GerdQ, a tool for the diagnosis and management of gastro-oesophageal reflux disease in primary care. Aliment Pharmacol Ther. 2009;30 (10):1030-1038. doi:10.1111/j.1365-2036.2009.04142.x

16. Jung HK. Epidemiology of gastroesophageal reflux disease in Asia: a systematic review. J Neurogastroenterol Motil. 2011;17(1):14. doi:10.5056/jnm.2011.17.1.14

17. Karim S, Ali H, Zehra SN, Faryal A, Khalid T, Mujtaba G. Anthropometric modification can be useful for gastro-esophageal reflux disease symptoms; which parameter should be targeted most? In a Tertiary Care Hospital at Karachi. Natl Editor Advisor Board. 2019;30(8):59.

18. Warsi I, Ahmed J, Younus A, et al. Risk factors associated with oral manifestations and oral health impact of gastro-oesophageal reflux disease: a multicentre, cross-sectional study in Pakistan. BMJ Open. 2019;9(3):e021458. doi:10.1136/bmjopen-2017-021458

19. Alrashed AA, Aljammaz KI, Pathan A, et al. Prevalence and risk factors of gastroesophageal reflux disease among Shaqra University students, Saudi Arabia. J Fam Med Prim Care. 2019;8(2):462. doi:10.4103/jfmpc.jfmpc_443_18

20. Halawani H, Banoon S. Prevalence and determinants of gastroesophageal reflux disease and the risk factors among adult patients attending Al-Iskan primary health care center in Makkah, 2020. Cureus. 2020;12(9):e10535.

21. Chowdhury SD, George G, Ramakrishna K, et al. Prevalence and factors associated with gastroesophageal reflux disease in southern India: a community-based study. Indian J Gastroenterol. 2019;38 (1):77-82. doi:10.1007/s12664-018-00931-6

22. City, Better Life, and E. Assessment. Urbanization and health. Bull World Health Organ. 2010;88(4):245-246.

23. Kariri AM, Darraj MA, Wassly A, et al. Prevalence and risk factors of gastroesophageal reflux disease in Southwestern Saudi Arabia. Cureus. 2020;12(1):e6626. 
24. Alkhathami AM, Alzahrani AA, Alzhrani MA, Alsuwat OB, Mahfouz MEM. Risk factors for gastroesophageal reflux disease in Saudi Arabia. Gastroenterol Res. 2017;10(5):294. doi:10.14740/gr906w

25. Kim O, Jang HJ, Kim S, et al. Gastroesophageal reflux disease and its related factors among women of reproductive age: Korea Nurses' Health Study. BMC Public Health. 2018;18(1):1-8. doi:10.1186/ s12889-018-6031-3

26. Chang P, Friedenberg F. Obesity and GERD. Gastroenterol Clin. 2014;43(1):161-173. doi:10.1016/j.gtc.2013.11.009

27. Ahmed S, Jamil S, Shaikh H, Abbasi M. Effects of Life style factors on the symptoms of gastro esophageal reflux disease: a cross sectional study in a Pakistani population. Pak J Med Sci. 2020;36(2):115.

28. Wang H-Y, Leena KB, Plymoth A, et al. Prevalence of gastro-esophageal reflux disease and its risk factors in a community-based population in southern India. BMC Gastroenterol. 2016;16(1):1-6. doi:10.1186/s12876-016-0452-1
29. Kahrilas P, Gupta R. Mechanisms of acid reflux associated with cigarette smoking. Gut. 1990;31(1):4-10. doi:10.1136/gut.31.1.4

30. Johnson T, Gerson L, Hershcovici T, Stave C, Fass R. Systematic review: the effects of carbonated beverages on gastro-oesophageal reflux disease. Aliment Pharmacol Ther. 2010;31(6):607-614. doi:10.1111/j.1365-2036.2010.04232.x

31. Siddiqui M, Hameed R, Nadeem M, et al. Obesity in Pakistan; current and future perceptions. J Curr Trends Biomed Eng Biosci. 2018;17:001-004.

32. Basit A, Younus BB, Waris N, Fawwad A. Prevalence of tobacco use in urban and rural areas of Pakistan; a sub-study from second National Diabetes Survey of Pakistan (NDSP) 2016-2017. Pak J Med Sci. 2020;36(4):808. doi:10.12669/pjms.36.4.1705
Risk Management and Healthcare Policy

\section{Publish your work in this journal}

Risk Management and Healthcare Policy is an international, peerreviewed, open access journal focusing on all aspects of public health, policy, and preventative measures to promote good health and improve morbidity and mortality in the population. The journa welcomes submitted papers covering original research, basic science, clinical \& epidemiological studies, reviews and evaluations,

\section{Dovepress}

guidelines, expert opinion and commentary, case reports and extended reports. The manuscript management system is completely online and includes a very quick and fair peer-review system, which is all easy to use. Visit http://www.dovepress.com/testimonials.php to read real quotes from published authors. 